\title{
A MUDANÇA DA CONTAGEM DE PRAZO NO NOVO CÓDIGO DE PROCESSO CIVIL E O PRINCÍPIO DA CELERIDADE PROCESSUAL
}

\author{
Camila Lopes ${ }^{1}$ \\ Mariângela Milhoranza²
}

Resumo: O presente estudo tem como objetivo analisar as mudanças trazidas pelo Novo Código de Processo Civil referente à contagem dos prazos processuais à luz do princípio da celeridade processual, positivado no artigo $5^{3 \circ}$, inciso LXXVIII da Constituição Federal Brasileira, no rol dos direitos fundamentais. A principal mudança se dá acerca dos dias em que os prazos se interrompem ou correm normalmente, já que o CPC de 2015 estabelece que os prazos não serão mais contínuos e computar-se-ão somente os dias úteis. Para a fundamentação, foram utilizadas pesquisas doutrinárias, bem como a legislação do Código de Processo Civil atual e Código de Processo Civil publicado em março de 2015 que entrará em vigor um ano após a sua publicação, para que se pudesse obter um estudo comparativo neste período de vacatio legis.

Palavras-chave: prazos processuais; Novo Código de Processo Civil; celeridade processual;

Abstract: This text has as objective analyze the changes of Civil Process New Code regarding trial deadline counting that has as principle speed trial established in section 5, subsection LXXVIII of Brazilian Constitution, in fundamental rights category. The main change is about days in that deadlines are interrupted or it continues normally, since Civil Process Code (2015) establishes that deadlines will not be continuos and it will be calculated only in working days. For substantiate, it has been used doctrinaire researches, as well as current Civil Process Code published on March, 2015, it will come into force one year its publication. Through douctrinare researches has obtained a comparative study in vacatio legis period.

Keywords: trial deadline, deadline counting, Civil Process New Code, speed trial.

\footnotetext{
${ }^{1}$ Acadêmica do Curso de Direito na UNICNEC.

${ }^{2}$ Prof ${ }^{2}$. Dra. em Direito, no Curso de Direito IMED.

${ }^{3}$ Art. $5^{\circ}$ Todos são iguais perante a lei, sem distinção de qualquer natureza, garantindo-se aos brasileiros e aos estrangeiros residentes no País a inviolabilidade do direito à vida, à liberdade, à igualdade, à segurança e à propriedade, nos termos seguintes: LXXVIII a todos, no âmbito judicial e administrativo, são assegurados a razoável duração do processo e os meios que garantam a celeridade de sua tramitação.
} 


\section{INTRODUÇÃO}

O Novo Código de Processo Civil publicado em março de 2015 que entrará em vigor em março de 2016 abarca inúmeras inovações. No tocante aos prazos processuais a precípua mudança ocorre na contagem destes, ou seja, como eles correrão a partir da entrada em vigor da nova lei.

O Código de Processo Civil vigente estabelece que o prazo estabelecido pela lei ou pelo juiz é contínuo, não se interrompendo nos feriados, mas apenas pela superveniência de férias forense. Assim os prazos correm normalmente todos os dias da semana, exceto se o dies a quo (termo inicial) ou dies ad quem (termo final) coincidir com um dia em que não há expediente forense.

Já no Código Civil de 2015 essas regras foram estabelecidas ao contrário, não se computarão mais os feriados e finais e de semana, nesses dias os prazos se interromperão. Ademais, foi mantida a regra da suspensão dos prazos nas férias forenses.

Estas mudanças estão intrinsecamente ligadas ao princípio constitucional da celeridade processual, estabelecido na Constituição Federal Brasileira de 1988 , artigo $5^{\circ}$, inciso LXXVIII, como um direito fundamental de todos.

O presente estudo busca apresentar que as mudanças trazidas pelo Código Civil de 2015 fere diretamente o princípio da celeridade processual, uma vez que os processos tramitarão de forma mais lenta, pois as partes terão mais tempo para praticar os atos processuais.

Para tanto, o estudo apresenta-se na forma de artigo científico, tendo como embasamento a pesquisa doutrinária pela análise de material bibliográfico, baseando-se nas teorias elaboradas por escritores de vasto conhecimento jurídico, expondo, interpretando e comparando-as. 


\section{OS PRAZOS PROCESSUAIS NO CÓDIGO PROCESSUAL CIVIL DE 1973}

\subsection{Conceito}

Prazo processual é o espaço de tempo em que deve ser realizado um ato processual. Prazos são lapsos temporais que existem entre dois termos dentro dos quais se prevê a oportunidade para uma ação ou omissão. ${ }^{4}$ Pode-se dizer que é o espaço de tempo entre o termo inicial (dies a quo) e o termo final (dies ad quem) pelo primeiro, nasce à faculdade de a parte promover o ato; pelo segundo, extingue-se a faculdade, tenha ou não sido levado a efeito o ato ${ }^{5}$. Termo inicial é quando se inicia a contagem do prazo, e termo final é o momento em que o prazo se extingue.

O ordenamento jurídico brasileiro não prevê prazos apenas para as partes, mas também para os juízes e auxiliares. Os prazos existem no processo para balizar no tempo o exercício das diversas posições jurídicas que os seus participantes titularizam ao longo do tempo ${ }^{6}$.

A doutrina entende como prazos próprios aqueles que devem ser cumpridos pelas partes, os prazos próprios existem para balizar o exercício de direitos e o desempenho de ônus ao longo do procedimento e impróprios aqueles fixados para os juízes e auxiliares de justiça, estes existem para moldar o cumprimento de deveres ${ }^{7}$. A inobservância dos prazos próprios acarreta desvantagem somente para aquele que o descumpriu, daí a denominação de prazos próprios para os fixados às partes e de prazos impróprios aos dos órgãos judiciários, já que a inobservância destes não decorre consequência ou efeito processual ${ }^{8}$.

O Código estabelece a maioria dos prazos, estes são denominados pela doutrina como prazos legais. Quando a lei for omissa, o juiz determinará os

\footnotetext{
${ }^{4}$ MARINONI, ARENHART, MITIDIERO, 2015, p.118

5 THEODORO JÚNIOR, 2010, p.251

${ }^{6}$ MARINONI, ARENHART, MITIDIERO, 2015, p.118

${ }^{7}$ MARINONI, ARENHART, MITIDIERO, op. cit, p.119

8 THEODORO JÚNIOR, 2010, p.251
} 
prazos, de acordo com artigo $177^{9}$, estes são conhecidos como prazos judiciais. Quando não houver determinação expressa e nem for fixado pelo juiz, o prazo será de 5 dias úteis, conforme disposto no artigo $185^{10}$. Já os prazos convencionais são aqueles que resultam de acordo entre as partes.

Os prazos, ainda podem ser comuns ou particulares. Serão comuns quando forem destinadas a ambas as partes, ou particulares quando forem destinado somente a uma delas.

Quanto à natureza, os prazos podem ser dilatórios ou peremptórios. Prazos dilatórios, são aqueles, que segundo o artigo 181 do CPC, mesmo havendo previsão na lei, podem ser alterados pela vontade das partes ou pelo juiz. Estabelece o artigo 181 que "podem as partes, de comum acordo, reduzir ou prorrogar o prazo dilatório; a convenção, porém, só tem eficácia se, requerida antes do vencimento do prazo, se fundar em motivo legítimo".

Prazos peremptórios são aqueles que nem as partes nem o juiz podem dispor sobre eles. Estabelece o artigo 182, "é defeso às partes, ainda que todas estejam de acordo, reduzir ou prorrogar os prazos peremptórios". Porém, o mesmo artigo prevê exceções: "o juiz poderá, nas comarcas onde for difícil o transporte, prorrogar quaisquer prazos, mas nunca por mais de sessenta dias". O parágrafo único do referido dispositivo legal ainda diz que "em caso de calamidade pública, poderá ser excedido o limite previsto neste artigo para a prorrogação de prazos".

Também podem ser de atuação, quando naquele lapso temporal as partes tenham o dever de fazer algo, ou de espera, quando as partes não poderão fazer nada antes de um tempo mínimo.

\footnotetext{
${ }^{9}$ Art. 177. Os atos processuais realizar-se-ão nos prazos prescritos em lei. Quando esta for omissa, o juiz determinará os prazos, tendo em conta a complexidade da causa.

${ }^{10}$ Art. 185. Não havendo preceito legal nem assinação pelo juiz, será de 5 (cinco) dias o prazo para a prática de ato processual a cargo da parte.
}

\section{DIREITO, CULTURA E CIDADANIA}




\subsection{Previsão legal no CPC de 1973}

O tempo e os prazos dos atos processuais estão inseridos no Título V dos atos processuais. Os Capítulo II, Seção I trata do tempo, dos artigos 172 ao 175. Capítulo III, trata dos prazos, dos artigos 177 ao 199.

\subsection{Contagem dos prazos}

A forma de contagem dos prazos processuais está prevista no artigo $184^{11}$ do CPC atual, em regra são contados em dias, não computando o dia do começo (dies a quo)e incluindo o dia do fim (dies ad quem), em termos de contagem dos prazos esta é a regra mais importante.

O artigo $241^{12}$ estabelece algumas regras quanto à fixação do dies a quo, são elas:

1) quando a citação ou intimação for feita pelos correios, o dies a quo, é o dia em que for juntado aos autos o aviso de recebimento;

2) quando a citação ou intimação for feita por oficial de justiça, o prazo inicia da juntada do mandado cumprido aos autos;

3) quando houver vários réus, o prazo inicia da juntada aos autos do último aviso de recebimento ou mandado citatório cumprido;

4) quando $o$ ato se realizar em cumprimento de carta de ordem, precatório ou rogatória, o termo inicial será da data da juntada aos autos devidamente cumprida;

5) quando a citação for por edital, a termo a quo será a partir do termo final do prazo estipulado pelo juiz no mesmo edital para aperfeiçoamento da diligência.

\footnotetext{
${ }^{11}$ Art. 184. Salvo disposição em contrário, computar-se-ão os prazos, excluindo o dia do começo e incluindo o do vencimento.

${ }^{12}$ Art. 241. Começa a correr o prazo: I - quando a citação ou intimação for pelo correio, da data de juntada aos autos do aviso de recebimento; II - quando a citação ou intimação for por oficial de justiça, da data de juntada aos autos do mandado cumprido; III - quando houver vários réus, da data de juntada aos autos do último aviso de recebimento ou mandado citatório cumprido; IV - quando $o$ ato se realizar em cumprimento de carta de ordem, precatória ou rogatória, da data de sua juntada aos autos devidamente cumprida;
}

\section{DIREITO, CULTURA E CIDADANIA}


No que se refere ao dies ad quem, ou termo final do prazo as regras estão elencadas nos incisos do artigo 184 do CPC, ficando estabelecido que o prazo será prorrogado nas seguintes hipóteses:

1. o vencimento cair em feriado;

2. for determinado o fechamento do fórum;

3. o expediente forense for encerrado antes da hora normal;

Não se inclui o dia do início da contagem, haja vista a impossibilidade de a parte utilizar as 24 horas do dia em que recebe a intimação, que é o marco inicial dos prazos (artigo 240) ${ }^{13}$ o que ocasionaria redução do prazo legal. Em relação ao último dia isso não ocorre, já que a parte tem o conhecimento prévio e poderá desfrutá-lo integralmente. Ressalta-se que o prazo legal ou mesmo o estabelecido pelo juiz, são contínuos, não se interrompendo nos finais de semana nem nos feriados, (artigo 178) ${ }^{14}$, exceto se o dia final ou inicial corresponder a um feriado ou final de semana, sendo prorrogado o início da contagem para o primeiro dia útil subsequente. Dia útil, para contagem dos prazos corresponde aos dias em que há expediente forense, e que 0 expediente não tenha iniciado mais tarde ou encerrado mais cedo.

Sábados, domingos e feriados são considerados dias não-úteis, as férias forenses se equiparam aos feriados, férias forenses são as paralisações que afetam, regular e coletivamente, durante determinados dias do ano, todo o funcionamento do juízo. ${ }^{15}$ As férias se diferem dos feriados por nos remeter à ideia de suspensão dos serviços por um período distendido, enquanto o feriado diz respeito à um determinado dia.

As férias forenses possuem efeito suspensivo dos prazos, não importando se o prazo é dilatório ou peremptório, assim o curso do prazo é suspenso e volta a correr no primeiro dia útil seguinte ao termo das férias (artigo 179) ${ }^{16}$.

\footnotetext{
${ }^{13}$ Art. 240. Salvo disposição em contrário, os prazos para as partes, para a Fazenda Pública e para o Ministério Público contar-se-ão da intimação.

${ }_{14}^{14}$ Art. 178. O prazo, estabelecido pela lei ou pelo juiz, é contínuo, não se interrompendo nos feriados.

${ }^{15}$ THEODORO JUNIOR, 2010, p.248

${ }^{16}$ Art. 179. A superveniência de férias suspenderá o curso do prazo; o que lhe sobejar recomeçará a correr do primeiro dia útil seguinte ao termo das férias.
} 
Entretanto, quando se trata de prazo decadencial, bem como 0 prescricional, não há suspensão, caso o seu término ocorra em período de férias ou em feriados, a parte deverá exercer seu direito em tempo hábil, mesmo que em dias não-úteis, sob pena de decair do seu direito.

O artigo $180^{17}$ prevê a hipótese de suspensão do prazo por obstáculo criado pela parte, ou ocorrendo qualquer uma das hipóteses do artigo 265. A interrupção importa em cortar-se o prazo que ainda flui e devolvê-lo à parte por inteiro depois de cessada a causa de interrupção. Com a suspensão, cessa a contagem do prazo, que só recomeça no primeiro dia útil seguinte ao seu termo. E, esse primeiro dia também se computa, já que não pode ser considerado dies a quo do prazo já iniciado anteriormente.

Outro tema pertinente na seara dos prazos processuais é o tema da preclusão. Segundo o artigo 183, "decorrido o prazo, extingue-se, independentemente de declaração judicial, o direito de praticar o ato". Preclusão é a perda, extinção ou consumação de uma faculdade processual em função de ter-se alcançado os limites assinalados pela legislação ao seu exercício ${ }^{18}$. Tal fenômeno que se perfaz àquele que se manteve inerte, podendo ser as partes ou o juiz, pode ser temporal, lógica ou consumativa. Preclusão temporal é a perda da faculdade ou direito processual, que se extinguiu por não exercício em tempo útil ${ }^{19}$.

Preclusão lógica é a extinção da faculdade processual à vista de um comportamento contraditório, isto é, da prática de um ato incompatível com aquele que se pretende realizar. Já a consumativa diz respeito à consumação da faculdade processual em face do seu já exercício ${ }^{20}$.

A preclusão, junto com os prazos processuais, baliza uma segura evolução do procedimento ${ }^{21}$, surge a partir da necessidade de que todas as etapas do processo devem se dar de maneira sucessiva, permitindo, assim que

\footnotetext{
17 Art. 180. Suspende-se também o curso do prazo por obstáculo criado pela parte ou ocorrendo qualquer das hipóteses do art. 265, I e III; casos em que o prazo será restituído por tempo igual ao que faltava para a sua complementação.

${ }^{18}$ MARINONI, ARENHART, MITIDIERO, 2015, p.119

${ }^{19}$ THEODORO JÚNIOR, 2010, p.260

${ }^{20}$ MARINONI, ARENHART, MITIDIERO, 2015, p.119

${ }^{21}$ MARINONI, ARENHART, MITIDIERO, 2015, p.118
}

\section{DIREITO, CULTURA E CIDADANIA}


o processo siga em frente, dirigindo-se ao seu fim, ou seja, à efetiva prestação da tutela jurisdicional. ${ }^{22}$

Conforme já dito anteriormente, o Código prevê também prazos para os juízes e auxiliares, ao juiz é dado os seguintes prazos: a) dois dias para despachos de expedientes, conforme artigo $\left.189^{23}, \mathrm{I} ; \mathrm{b}\right)$ dez dias para decisões interlocutórias (artigo 189, II) ${ }^{24}$, sentenças (artigo 456) ${ }^{25}$. Em havendo descumprimento dos prazos pelo juiz, as partes, ou o Ministério Público poderá representar ao Presidente do Tribunal de Justiça contra o juiz que excedeu os prazos previstos em lei (artigo 198, primeira parte) ${ }^{26}$.

Para os chefes de secretaria e escrivães, de acordo com artigo $190^{27}$ os prazos são: a) 24 horas para remeter aos autos conclusos; b) 48 horas para executar os demais atos do processo. O cumprimento destes prazos será fiscalizado pelo juiz (artigo 193) ${ }^{28}$, quando o atraso não for motivado o juiz mandará instaurar procedimento administrativo, na forma da lei da Organização Judiciário (artigo 1950) 29 .

O Ministério Público e a Fazenda pública possuem prazos diferenciados, reza o artigo 188 que "computar-se-á em quádruplo o prazo para contestar e em dobro para recorrer, quando a parte for a Fazenda Pública ou o Ministério Público". Isto se dá em razão das notórias dificuldades de ordem burocrática que se notam no funcionamento dos serviços jurídicos da Administração Pública.

${ }^{22}$ THEODORO JÚNIOR, 2010, p. 260

${ }^{23}$ Art. 189. O juiz proferirá: I - os despachos de expediente, no prazo de 2 (dois) dias;

${ }^{24}$ Art. 189. O juiz proferirá: II - as decisões, no prazo de 10 (dez) dias.

${ }^{25}$ Art. 456. Encerrado o debate ou oferecidos os memoriais, o juiz proferirá a sentença desde logo ou no prazo de 10 (dez) dias

${ }^{26}$ Art. 198. Qualquer das partes ou o órgão do Ministério Público poderá representar ao presidente do Tribunal de Justiça contra o juiz que excedeu os prazos previstos em lei. Distribuída a representação ao órgão competente, instaurar-se-á procedimento para apuração da responsabilidade. O relator, conforme as circunstâncias, poderá avocar os autos em que ocorreu excesso de prazo, designando outro juiz para decidir a causa.

${ }^{27}$ Art. 190. Incumbirá ao serventuário remeter os autos conclusos no prazo de 24 (vinte e quatro) horas e executar os atos processuais no prazo de 48 (quarenta e oito) horas, contados: I - da data em que houver concluído o ato processual anterior, se Ihe foi imposto pela lei; II - da data em que tiver ciência da ordem, quando determinada pelo juiz.

${ }^{28}$ Art. 193. Compete ao juiz verificar se o serventuário excedeu, sem motivo legítimo, os prazos que este Código estabelece.

${ }^{29}$ Art. 195. O advogado deve restituir os autos no prazo legal. Não o fazendo, mandará o juiz, de ofício, riscar o que neles houver escrito e desentranhar as alegações e documentos que apresentar. 
O conceito de Fazenda Pública abrange a União, Estados, Distrito Federal e Municípios, e também suas autarquias. As empresas públicas e as sociedades de economia mista, entidades integrantes da administração indireta, sendo pessoas jurídicas de direito privado, não integram o conceito de Fazenda Pública ${ }^{30}$.

Conforme leciona Pontes de Miranda,

O artigo 188 não concerne apenas ao procedimento ordinário, nem só ao processo de conhecimento. Quer seja ordinário, ou não, o procedimento, a Fazenda Pública ou o Ministério Público, tem em quádruplo o prazo para contestar. ${ }^{31}$

Outro privilégio também é dado aos litisconsortes, sempre que estes tiverem diferentes procuradores serão contados em dobro os prazos para contestar, para recorrer e para falar nos autos (artigo 191 ${ }^{32}$ ). No poder de contestar, está implícito o de reconvir, excepcionar, contestar a reconvenção, opor embargos ao mandado monitório, impugnar os embargos de devedor.

Porém, de acordo com matéria sumulada pelo STF, quando apenas um dos litisconsortes houver sucumbido não há motivos para se aplicar o referido artigo. A Súmula 641 do STF diz que: "Não se conta em dobro o prazo para recorrer, quando um só dos litisconsortes haja sucumbido".

\section{OS PRAZOS PROCESSUAIS NO CÓDIGO DE PROCESSO CIVIL DE 2015}

A mudança trazida pelo Novo Código de Processo Civil no tocante aos prazos processuais diz respeito aos dias em que o prazo será interrompido, como nos finais de semana e feriados, não alterando em nenhum aspecto $o$

${ }^{30}$ O Decreto-Lei no 200 , de 25 de fevereiro de 1967, com as alterações introduzidas pelo Decreto-Lei no 900, de 29 de setembro de 1969, estabeleceu uma distinção entre os órgãos da Administração Indireta. Segundo o decreto, tão somente as autarquias são pessoas de direito público. As empresas públicas e as sociedades de economia mista são pessoas de direito privado que, vinculadas à Fazenda Pública, não gozam dos benefícios a esta concedidos como pessoa de direito público.

${ }_{31}$ MIRANDA, 1997, p. 118 apud BRENNER, Ana Cristina. Prazos (CPC, art. 177 a 199). Revista Páginas de Direito, Porto Alegre, ano 5, no 257, 12 de maio de 2005. Disponível em: http://www.tex.pro.br/home/artigos/102-artigos-mai-2005/5185-prazos-cpc-arts-177-a-199

${ }^{32}$ Art. 191. Quando os litisconsortes tiverem diferentes procuradores, ser-lhes-ão contados em dobro os prazos para contestar, para recorrer e, de modo geral, para falar nos autos. 
conceito de prazos. Portanto, quanto ao conceito, este permanece o mesmo já asseverado anteriormente.

No Capítulo II, estão previstas as regras pertinentes a matéria do tempo e do lugar doas atos processuais, do artigo 212 ao 216. O Capítulo III, Seção I, trata das disposições gerais acerca dos prazos, do artigo 218 ao 232. No mesmo Capítulo, Seção II estão previstas a verificação do prazo e suas penalidades.

Aqui é que se verifica as mudanças trazidas pelo CPC de 2015, a partir da entrada em vigor do Novo Código não serão mais computados, para a contagem dos prazos os finais de semana e feriados, logo os prazos fluirão somente em dias úteis, se interrompendo nos finais de semana e feriados, e voltando à fluir no primeiro dia útil subsequente à sua interrupção.

A regra do artigo $177^{33}$ do CPC vigente, que diz que os atos processuais serão realizados nos prazos prescritos em lei, e quando a lei for omissa o juiz determinará os prazos, foi mantida no artigo 218 do Novo CPC, com a inclusão de alguns parágrafos:

Art. 218. Os atos processuais serão realizados nos prazos prescritos em lei.

$\S 1^{\circ}$ Quando a lei for omissa, o juiz determinará os prazos em consideração à complexidade do ato.

$\S 2^{\circ}$ Quando a lei ou o juiz não determinar prazo, as intimações somente obrigarão a comparecimento após decorridas 48 (quarenta e oito) horas.

$\S$ 3o Inexistindo preceito legal ou prazo determinado pelo juiz, será de 5 (cinco) dias o prazo para a prática de ato processual a cargo da parte.

§ 4ํㅗ Será considerado tempestivo 0 ato praticado antes do termo inicial do prazo.

\footnotetext{
${ }^{33}$ Art. 173. Durante as férias e nos feriados não se praticarão atos processuais. Excetuam-se: I - a produção antecipada de provas (art. 846); II - a citação, a fim de evitar o perecimento de direito; e bem assim o arresto, o sequestro, a penhora, a arrecadação, a busca e apreensão, 0 depósito, a prisão, a separação de corpos, a abertura de testamento, os embargos de terceiro, a nunciação de obra nova e outros atos análogos.
} 
O artigo $178^{34}$ do atual código dispõe que tanto o prazo estabelecido pela lei, quanto o prazo estabelecido pelo juiz é contínuo e não se interromperá nos feriados. Este artigo foi alterado pelo art. 219, do CPC/15:

Art. 219. Na contagem de prazo em dias, estabelecido por lei ou pelo juiz, computar-se-ão somente os dias úteis.

Parágrafo único. O disposto neste artigo aplica-se somente aos prazos processuais. ${ }^{35}$

É neste ponto que se dá a maior discussão trazida pelo Novo CPC referente aos prazos processuais, visto que os processos caminharão de forma mais lenta, ferindo assim, o Princípio Constitucional da Celeridade processual, que será exposto mais adiante.

Entretanto, o artigo 179, que prevê a suspenção dos prazos pela superveniência de férias corresponde ao artigo $220^{36}$ do $\mathrm{CPC} / 15$, esta regra foi mantida, porém, ressalvadas as férias individuais e os feriados instituídos por lei, os juízes, os membros do Ministério Público, da Defensoria Pública e da Advocacia Pública e os auxiliares da Justiça exercerão suas atribuições durante o período previsto no caput. E durante a suspensão do prazo, não se realizarão audiências nem sessões de julgamento.

O artigo 180 do $\mathrm{CPC} / 73$, estabelece que o curso do prazo por obstáculo criado pela parte ou ocorrendo qualquer das hipóteses do artigo 265 , que prevê a suspenção do processo, foi alterado pelo artigo $221^{37}$ do CPC/15. A única mudança é que artigo 265 foi alterado pelo artigo $313^{38}$.

\footnotetext{
${ }^{34}$ Art. 178. O prazo, estabelecido pela lei ou pelo juiz, é contínuo, não se interrompendo nos feriados.

${ }^{35}$ Art. 219. Na contagem de prazo em dias, estabelecido por lei ou pelo juiz, computar-se-ão somente os dias úteis.

${ }^{36}$ Art. 220. Suspende-se o curso do prazo processual nos dias compreendidos entre 20 de dezembro e 20 de janeiro, inclusive.

${ }^{37}$ Art. 221. Suspende-se o curso do prazo por obstáculo criado em detrimento da parte ou ocorrendo qualquer das hipóteses do art. 313, devendo o prazo ser restituído por tempo igual ao que faltava para sua complementação.

${ }^{38}$ Art. 313. Suspende-se o processo: I - pela morte ou pela perda da capacidade processual de qualquer das partes, de seu representante legal ou de seu procurador; II - pela convenção das partes; III - pela arguição de impedimento ou de suspeição; IV- pela admissão de incidente de resolução de demandas repetitivas; $V$ - quando a sentença de mérito: a) depender do julgamento de outra causa ou da declaração de existência ou de inexistência de relação jurídica que constitua o objeto principal de outro processo pendente; b) tiver de ser proferida somente após a verificação de determinado fato ou a produção de certa prova, requisitada a
} 


\section{Os artigos 181, 182 e 183 do CPC atual, não foram alterados no Novo} CPC, correspondendo aos artigos $222^{39}$ e $223^{40}$.

O artigo 184 do CPC atual estabelece que, salvo disposição em contrário, os prazos serão computados excluindo o dia do começo e incluindo o dia do seu final. Tal regra foi mantida pela nova lei, no entanto a hipótese de que trata o parágrafo $1^{\circ}$, inciso I e II (1973), estabelece que o prazo será prorrogado no dia em que for determinado o fechamento do fórum, ou expediente forense encerrar antes do normal, foi suprimido, por tratar de feriado prevista no artigo $216^{41}$, do novo CPC.

Os artigos 185, 186, 187 do CPC/73 mantém sua redação nos artigos $218^{42}, 225^{43}$ e $227^{44}$ do CPC/15. O art. 188 do CPC/73, que prevê prazos em

outro juízo; VI - por motivo de força maior; VII - quando se discutir em juízo questão decorrente de acidentes e fatos da navegação de competência do Tribunal Marítimo; VIII - nos demais casos que este Código regula.§ 1ํำ $\mathrm{Na}$ hipótese do inciso I, o juiz suspenderá o processo, nos termos do art. 689.§ $2^{\circ}$ Não ajuizada ação de habilitação, ao tomar conhecimento da morte, 0 juiz determinará a suspensão do processo e observará o seguinte: I - falecido o réu, ordenará a intimação do autor para que promova a citação do respectivo espólio, de quem for o sucessor ou, se for o caso, dos herdeiros, no prazo que designar, de no mínimo 2 (dois) e no máximo 6 (seis) meses; II - falecido o autor e sendo transmissível o direito em litígio, determinará a intimação de seu espólio, de quem for o sucessor ou, se for o caso, dos herdeiros, pelos meios de divulgação que reputar mais adequados, para que manifestem interesse na sucessão processual e promovam a respectiva habilitação no prazo designado, sob pena de extinção do processo sem resolução de mérito. $\S 3^{\circ}$ No caso de morte do procurador de qualquer das partes, ainda que iniciada a audiência de instrução e julgamento, o juiz determinará que a parte constitua novo mandatário, no prazo de 15 (quinze) dias, ao final do qual extinguirá o processo sem resolução de mérito, se o autor não nomear novo mandatário, ou ordenará 0 prosseguimento do processo à revelia do réu, se falecido o procurador deste. $\S 4^{\circ} \mathrm{O}$ prazo de suspensão do processo nunca poderá exceder 1 (um) ano nas hipóteses do inciso $V$ e 6 (seis) meses naquela prevista no inciso II.§ $5^{\circ} \mathrm{O}$ juiz determinará o prosseguimento do processo assim que esgotados os prazos previstos no $\S 4^{\circ}$.

${ }^{39}$ Art. 222. Na comarca, seção ou subseção judiciária onde for difícil o transporte, o juiz poderá prorrogar os prazos por até 2 (dois) meses.

${ }^{40}$ Art. 223. Decorrido o prazo, extingue-se o direito de praticar ou de emendar o ato processual, independentemente de declaração judicial, ficando assegurado, porém, à parte provar que não o realizou por justa causa.

${ }^{41}$ Art. 216. Além dos declarados em lei, são feriados, para efeito forense, os sábados, os domingos e os dias em que não haja expediente forense.

${ }^{42}$ Art. 218 . Os atos processuais serão realizados nos prazos prescritos em lei.§ $1^{\circ}$ Quando a lei for omissa, o juiz determinará os prazos em consideração à complexidade do ato. $\S 2^{\circ}$ Quando a lei ou o juiz não determinar prazo, as intimações somente obrigarão a comparecimento após decorridas 48 (quarenta e oito) horas. $\S 3^{\circ}$ Inexistindo preceito legal ou prazo determinado pelo juiz, será de 5 (cinco) dias o prazo para a prática de ato processual a cargo da parte.§ $4^{\circ}$ Será considerado tempestivo o ato praticado antes do termo inicial do prazo.

${ }^{43}$ Art. 225. A parte poderá renunciar ao prazo estabelecido exclusivamente em seu favor, desde que o faça de maneira expressa.

${ }^{44}$ Art. 227. Em qualquer grau de jurisdição, havendo motivo justificado, pode o juiz exceder, por igual tempo, os prazos a que está submetido. 
dobro para o MP e a Fazenda Pública contestar e em quádruplo para recorrer, foi alterado, no CPC /15. O artigo $180^{45}$ do Novo Código prevê prazo em dobro para o MP manifestar-se nos autos. O mesmo ocorreu com a Fazenda Pública, regra alterada pelo artigo $183^{46}$.

\title{
4 A MUDANÇA DA CONTAGEM DOS PRAZOS À LUZ DO PRINCÍPIO DA CELERIDADE PROCESSUAL
}

Com o advento da Reforma do Poder Judiciária, através da Emenda Constitucional o 45 de 08 de dezembro de 2004, o princípio da celeridade processual já presente entre os princípios constitucionais, foi elevado à categoria de direitos fundamentais. O objetivo de elevar o princípio a tal categoria é eliminar quaisquer resquícios que se restassem duvidosos acerca de sua aplicação, bem como agilizar a tramitação dos processos, porquanto a morosidade processual leva a sociedade desacreditar na justiça, neste sentido, Moura e Cardoso (2009):

\begin{abstract}
Um julgamento tardio perde progressivamente seu sentido reparador, na medida em que preteri o momento do reconhecimento judicial do direito. Transcorrido o tempo razoável para resolver a causa, a solução que vier posteriormente será injusta, a saber, a justiça injusta além de ser aquela que atua equivocadamente, também o é quando não julga quando deve. ${ }^{47}$
\end{abstract}

A razoável duração do processo, expressão utilizada pelo legislador, é abstrata e subjetiva, incumbindo, assim, aos doutrinadores e à jurisprudência interpretar de forma coerente o que se pode dizer por razoável duração do processo. A forma objetiva de interpretar este princípio é através dos prazos já estabelecidos em lei. Assim, havendo lei que os define, a forma objetiva de aplica-lo, Ihe conferindo eficácia jurisdicional, é a observação deles por todas

\footnotetext{
${ }^{45}$ Art. 180. O Ministério Público gozará de prazo em dobro para manifestar-se nos autos, que terá início a partir de sua intimação pessoal, nos termos do art. 183, § 1․․

${ }^{46}$ Art. 183. A União, os Estados e o Distrito Federal, os Municípios e as suas respectivas autarquias e fundações de direito público gozarão de prazo em dobro para todas as suas manifestações processuais, cuja contagem terá início a partir da intimação pessoal.

${ }^{47}$ MOURA, Fernando Galvão, CARDOSO, Raphael de Matos. Celeridade Processual: direito e garantia fundamental a positivação de princípios constitucionais.
} 
as partes envolvidas no processo, e como já asseverado anteriormente, caso haja inobservância dos prazos a parte perde o direito de praticar 0 ato processual.

O fenômeno da preclusão está diretamente ligado com o princípio da celeridade processual, haja vista a enorme insegurança jurídica que causaria caso as partes não tivessem limites temporais para praticar os atos processuais.

Não há como estabelecer uma regra absoluta do número de dias que cada processo irá demorar até seu chegar ao seu fim, já que circunstâncias, como a comarca em que o processo está tramitando, a dilatação dos prazos e as peculiaridades de cada processo poderão contribuir para maior ou menor rapidez do processo.

Para ter-se uma ideia do que seria um lapso temporal admissível e razoável, se faz necessário que cada ato processual seja realizado, observados outros princípios constitucionais, como o direito ao contraditório e ampla defesa, sem que estes firam a celeridade processual. São estes fatores que permitem a razoável duração do processo, quando andam junto com a rigorosa observação dos prazos processuais, tanto para as partes, quanto para os serventuários e juízes.

Tais fatores corroboram para que o tempo do processo seja coerente com o tempo das partes, ou seja, dirimir os conflitos à tempo de fazer valer a efetividade do processo.

A celeridade processual está prevista no artigo 5ำ, inciso LXXVIII, "a todos, no âmbito judicial e administrativo, são asseguradas a razoável duração do processo e os meio que garanta a celeridade de sua tramitação". Este inciso, foi acrescentado pela Emenda Constitucional n 45 de 08 de dezembro de 2004. 


\subsection{Algumas reflexões acerca da alteração da contagem de prazo e do princípio da celeridade}

Celeridade significa rapidez, característica daquele que é célere. O Princípio da Celeridade visa garantir à todos aqueles que ingressarem no Poder Judiciário tenham seus conflitos dirimido da forma mais célere possível. Já que, conforme ensina Pedro Lenza 48 "em algumas situações, a demora causada pela duração do processo e sistemática dos procedimentos, pode gerar total ineficácia do provimento requerido."

É certo que este não é o único princípio a ser observado nos processos. Outros princípios como a ampla defesa e direito ao contraditório devem ser sempre observados, todos os direitos fundamentais devem ser garantidos no mesmo patamar, pois não há hierarquia entre eles.

As mudanças trazidas pelo Novo Código de Processo Civil, traz menos efetividade à norma constitucional, ferindo o princípio da celeridade, porquanto, mais tempo para realizar os atos processuais, demorará ainda mais para que os processos cheguem ao seu destino, que é a tutela jurisdicional, conforme já asseverado anteriormente.

Isto significa que a atual morosidade observada hoje pela sociedade quanto à justiça brasileira, continuará igual, ou por vezes, até maior. O que acarretará ainda, maior descrédito dos cidadãos.

\section{CONCLUSÃO}

Com a elaboração do presente artigo, pode-se produzir um conjunto de constatações e análises, referentes ao atual Código de Processo Civil, ao Código de Processo Civil que entrará em vigor no ano de 2016, e ao Princípio da Celeridade Processual.

Fazendo um comparativo entre os dois Códigos de Processo à luz da celeridade processual, foi possível observar as mudanças trazidas pelo Novo

${ }^{48}$ LENZA, Pedro, 2010, p.799 
Código, no tocante aos prazos processuais, questionando assim, a sua (in)constitucionalidade, interpretando-o pelo prisma dos direitos fundamentais.

Embora haja divergências entre os operadores do direito, já que existe uma parcela que acredita que esta mudança não trará malefícios, pelo contrário, garantirá aos advogados, juízes e Ministério Público, o merecido descanso nos finais de semana, é imprescindível analisar quanto ela afetará o trâmite dos processos.

A morosidade com que se se desenvolvem os processos no Brasil é um dos fatores que levam a população desacreditar no Poder Judiciário. Por óbvio, que a interrupção dos prazos nos feriados e fins de semana importará maior lentidão à efetiva prestação da tutela jurisdicional, corroborando ainda mais para que se produza uma sociedade descrente na justiça.

A celeridade processual é um dos princípios basilares para a formação de um Estado Democrático de Direito, porquanto não pode ser tolerada a absurda duração do processo, visto que a delonga excessiva gera angústia e infelicidade nas partes litigantes.

Diante o exposto, constata-se que o princípio da celeridade processual é amplamente afrontado pelo Novo Código de Processo Civil, haja vista que o desenvolvimento processual dentro de um lapso temporal necessário se faz imperioso para que se atinja o seu verdadeiro escopo: a pacificação de uma demanda pela efetiva tutela jurisdicional.

\section{REFERÊNCIAS}

BRASIL. Constituição da República Federativa do Brasil de 1988.

Disponível em: <http://www.planalto.gov.br/ccivil_03/constituicao/Constituicao>. Acesso em: 28 set. 2015

BRASIL, Lei 5.869, 11 de Janeiro de 1973. Disponível em:

<http://www.planalto.gov.br/ccivil_03/leis/L5869compilada.htm>. Acesso em: 30 out. 2015.

BRASIL, Lei 13.105, 16 de Março de 2015. Disponível em: <www.planalto.gov.br/ccivil_03/leis/L5869compilada.htm>. Acesso em 30 set. 21015. 
BRENNER, Ana Cristina. Prazos (CPC, arts. 177 a 199). Disponível em: <http://www.tex.pro.br/home/artigos/102-artigos-mai-2005/5185-prazos-cpcarts-177-a-199>. Acesso em: 20 set. 2010.

GALVÃO, Fernando. CARDOSO, Raphael de Matos. Celeridade Processual: direito e garantia fundamental a positivação de princípios constitucionais. Disponível em: <http://www.feb.br/index.php/horarios2015/doc_details/341celeridade-processual-direito-e-garantia-fundamental-a-positivacao-deprincipios-constitucional>. Acesso em: 07 set. 2015.

LENZA, Pedro. Direito Constitucional Esquematizado. 14. ed. Saraiva, 2010. MARINONI, Luiz Guilherme; MITIDIERO, Daniel; ARENHART, Sergio Cruz. Novo Curso de Processo Civil. 1. ed. vol. 1, Revista dos Tribunais, 2015.

THEODORO JÚNIOR, Humberto. Curso de Direito Processual Civil. 51. ed. Vol.1, Editora Forense, 2010. 